\title{
Research and Part Implementation of Process Oriented Online Education Information System
}

\author{
Xue Mei Jiang \\ Teacher's College, Beihua University, Jilin, China
}

\begin{abstract}
In the context of internet applications, traditional learning management system has been an unprecedented challenge to the current distance education of adult students to fully understand the importance of the use of new media, necessity, and through part implementation of process oriented online education information system, which is the student population is widely popular media to develop and strengthen, so as to continuously improve the effectiveness, and improve the quality of personnel training. In this paper, the characteristics of the part implementation of process oriented online education information system, and how to use distance education of students as well as to strengthen the contemporary education.
\end{abstract}

\section{General instruction}

Distance education, also known as distance education, which goes beyond the barrier of time and space from the education, its principal means for teaching through television or the Internet and other media teaching as a carrier, which has a formal and traditional education sharp distinction, no longer need to school buildings and classrooms as a student must Venue. Using distance education students generally are not professional student, whose audience is mainly dominated amateur fellows. Because there is no limit class place, so the time and place of the class is not limited. Among the students in the learning process can also be aided learning through a variety of different ways a network, television broadcasting, as well as letter-face class research community and so on. modern distance education in various forms, inherent in distance education as the focus of education at the same time, also need to use a variety of media and a variety of teaching forms of action together, including correspondence and face to face, etc., while the students' self-learning can play a very important role. Modern Distance Education so that it can fully demonstrate the characteristics obtained, the characteristics of its teaching that the mutual separation between teachers and students, there is no form of face to face teaching, the system itself across the barrier between regions and between schools. Characteristics of distance education are: to achieve a mutual separation of teachers and students; and the way their teaching of information transmission can be specified transport system and the media in order to achieve; its method many forms coexist; and the biggest advantage is the freedom of choice Want regional and forms of learning. Distance education than traditional face to face in terms of time and space to break the barrier, and in expanding the teaching area while allowing more people access to the conditions of learning, not only that the process of teaching will greatly reduce the cost of inputs, and also the quality of teaching Contrary rise, not fall.

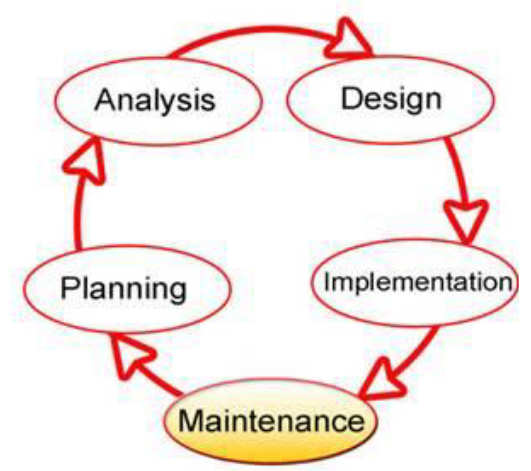

Figure 1. Part implementation of process oriented online education information system

On the development stage of distance education we can draw a conclusion very quickly in the international development of distance education, but this mode of education in our country there is a very large potential for development, to be excavated. The development of modern distance education can be said that the general trend, which is making development more quickly via the Internet as the primary carrier. As early as two thousand years of time, the world has more than one hundred countries have begun using remote education, not only that up to eighty-five percent of the world's institutions of higher learning has its own dedicated website, and in this one the most out of every four homes the school will have a pioneering online education platform as the basis 
for the promotion of their programs. Online education in Europe and America because of its network technology development started earliest, and therefore has become the industry leader in today's world; the scale of its development has been relatively grown.

\section{Overview of the teaching process theory}

Process, from literally is a program of development of things. The teaching is mainly the result of teaching and the pursuit of contrast, it is emphasized that the directivity of learning through the learning process of the guide to make students capable of a wide range of intellectual development, rather than a single process of thinking and the pursuit of thinking not focus on results, the resulting content and the like, such as the ability to solve practical problems is an important part of the process of teaching. To sum up, the students learn to think and grasp of knowledge is the process of teaching, cognitive and generation to respect for the students in the learning process of knowledge, the formation of knowledge system among, will enhance students' personal qualities as the ultimate goal, By the way according to a certain level of education, so that students can learn the process, to understand the link between practice and results, and thus in the process of being realized gain the experience, so that students' learning ability can eventually produce. To implement the process of teaching, teachers must change their ideas, accelerate Teachers' Role, respect cognitive law, respect for the students to explore the process of listening, speaking, reading and writing teaching, fully embodies the principle of the process of teaching. In the design and implementation of online education and the use of online education should also pay attention to when reflected in the teaching process.

Concluding the process of teaching and teaching is a relative term. In the context of teaching, teaching to the conclusion that refers to after repeated demonstration for the public recognition and acceptance of knowledge. Theoretical perspective, the conclusions of the so-called teaching is teaching at the end we hope to achieve. In fact, we have been accustomed to this "know" teaching method, in fact, in terms of the students are hurt. Although reluctant to accept such students, but did not digest, do not know how to digest. People feel dull; students will show conflicting emotions, knowledge and ability to not be able to get the conversion.

The idea is to make the process of teaching students through the teaching and get a new experience that refers to the experience in the exploration and acquisition of new knowledge and experience when new knowledge. Course objectives can be distinguished only with skills, attention to process and methods, attention to emotional attitude values. Here, the goal is not the teaching of the three objectives, but rather refers to the teaching of the three aspects, three-dimensional teaching goal epitomizes the new curriculum "people-oriented" and "development of students," the core idea. Wherein both the process or method, or "attitudes and values" are focusing on experiences and insights as well as changes in the thoughts and feelings of the students on the heart, it can not be conclusive (dominance, precision, specificity, operability) way to measure, both as the "knowledge and skills" corresponding to that part of the process of the target can be referred to.

Realization of objectives depends on the process of teaching, the following from the concept of law teaching; experimental teaching, exercises, data processing and teaching evaluation results highlight the procedural aspects:

1. Concept, law teaching. Students understand new concepts, the need to go through the stage of exploration and research, rather than direct conclusion of indoctrination. A good concept teaching is beginning in the process of establishing the need to invest a lot of time and effort.

2. Experimental teaching. Whether demonstration experiment or design of experiments, guide students to treat the problem of rational thinking, cultivate rational, logical and creative ability of students to deal with things.

3. The data processing. Data processing is an important part of science, and in the course of processing the data it is very meaningful. Experimentally measured data, to enable students to conduct yourself projections and analysis, reflection source link between data and conclusions, workout data processing capabilities of students, have more general data processing methods, a deeper understanding of knowledge, so that it can form a complete set of knowledge architecture system.

4. Exercise teaching. A certain amount of exercise training is essential, it can play through training exercises to consolidate and deepen the concepts and laws of this purely theoretical understanding of knowledge and ability on how to learn and use of knowledge. Exercise training is an important part of moderation, moderation exactly how to do a basic capability through a variety of experiential activities gradually, not overnight, so in the teaching activities must be strengthened and a sufficient amount of exercise training, and in teaching activities should focus on guiding and helping students to create a variety of topics scenarios.

5. The teaching evaluation. Traditional teaching evaluation mainly depends on mastery of the high school students to the book, including the number and depth of knowledge, mainly through the students usually practice, tests, examinations, assignments and classroom answering questions orally to the results of the statistical evaluation of student achievement, such approach ignores its own evaluation of the learner in terms of nonintelligence factors.

\section{Systems Business requirements analysis}


Zhejiang Pharmaceutical College as a full-time colleges and universities, the traditional mode of education gradually biggest drawbacks: the lack of teacher-student interaction in the classroom, can not effectively assess teaching effectiveness and the like; and real-time remote education when students and faculty ratio disparity when the interaction effects are minimal, but by time, place and existing network hardware and bandwidth constraints conditions, can not be widely used class of noncentralized adult learning scene. System main business work flow chart is as follows:

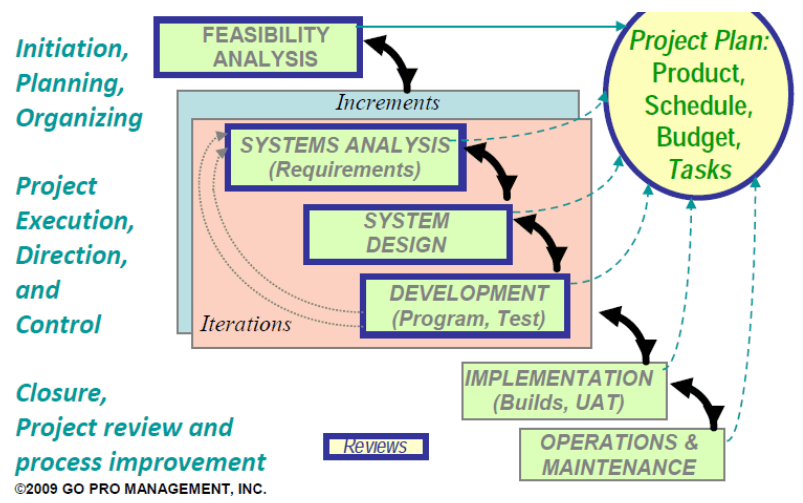

Figure 2. Project management and system development flow chart

Distance Education Information Management System workflow is as follows:

After approval by the administrator login system to learn, or to use an administrator direct the bulk registration. The system provides authorization capabilities course, the students of different major's authorization given to different courses.

Teaching is all aspects of information for maintenance and so on.

Into the teaching information resource library: including multimedia courseware, courseware material, and preparation of the course students may encounter difficult problems and answers Knowledge Learning resources and other inquiries.

Quizzes online classroom exercises, after the end of each lesson finished, completed after-school exercise test, in order to consolidate and test learning outcomes. The module automatically, in real-time scoring, all kinds of questions are used in the form of objective questions.

Online classroom is through online mock examinations system. School exercise test, the students complete a course of study, then arrange online simulation papers, upon request, in accordance with the specific requirements of the custom paper. For the sake of heavy process, light conclusions concept papers may allow students to repeat three times, and will provide the correct answer after each, take three papers of the highest points as the assessment points, simulation answers and exam papers are based on random mode.
Statistics by automatic learning outcomes: to provide fast, real-time statistics and effective learning outcomes. For example, school

When long learning, academic performance and other results.

Students or teachers or students in the class can see your learning progress situation. Flexible student learning plan based on a percentage of their course of study. The teacher will be based on the student's progress, learning the number of academic all-round understanding to facilitate the process of assessment.

Courses are classified according to provide students and teachers teaching answering specific modules, students and the lecturer here to explore more academic problem, the student common questions for everyone to share, thereby reducing the teacher to repeat answering questions, some students do not know Q. What brought the missing communication, interactive reduce the problem. According query statistics teacher student progress and found some learning behind schedule, active students are not learning, flexible to take measures, such as sending text messages or e-mail notification, urging students to learn on the platform. The level of activity will serve as one of the students answering procedural basis for assessment.

\section{System design}

Process of distance education system network is an important part of it, by helping with the management of the next match, and thus more reliable use of rich materials outside of the relevant disciplines, enabling multi-angle multi-level Modern Distance Education Services. The system is relatively more perfect realization of the combined visible and distance learning, making learning and exchanges between students and teachers to provide a good environment. In the analysis phase, we use object-oriented thinking and teaching methods and tools UML support system is analyzed to determine the logical structure of the system, which will be the basis for system design.

J2EE platform architecture shown on the basis of intelligence there is a further division, including the client tier, Web tier, business logic (Business Logic) layer and data access (Data Access) layer such as four further finegrained. Among the above-mentioned various levels, the code will be different corresponding compression, and added to the different components which, in the layer and the interaction layer, components and assemblies being among obtained using, in this case the code reusability will be greatly improved. The specific role of each layer is as follows:

Client layer: its underlying application is a Web browser, and by operating in these browsers being used to achieve its purpose and function. Its main role is for the entire interface and data display, and the user can also be achieved by this layer for system maintenance and data entry. 
Web layer: This layer is divided into two components being part of JSP and Servile, its core function is the Web among users sees dynamic content generation, which is typically dynamic content from the database through the business layer obtained.

Business logic layer: This layer serves huge, mainly targeted at some complex business logic to address it, most of these issues are separate properties, the layer normal work is mainly based on the conduct of the enterprise bean, its vast Most of logic are stored in the business logic layer (business Logic) in. Of course, the application server (Application Server) can automatically handle many services such as Transaction, Data Base Connection Pool and so on. The business logic is from resource management needs out, help developers to put more focus on how to build up high-quality applications.

Data Access Layer: its role in that database and information for effective control regulation, including a variety of different types of database access program management. The main work is when the business logic layer data access layer data access requests are to be made relevant data query, persistence operations to be supported when cent submit the appropriate data.

MVC (Model View Controller) that is an application depending on the division of labour is divided into three layers - model layer, view layer, control layer, is now more popular, widely used in software development and design patterns. MVC is a design pattern that emphasizes is how to separate the rational model program interface, business process logic. MVC has many advantages; it is widely used in the software industry of design patterns, help software engineering management, etc.

\section{Conclusion}

Paper based on the theory developed in these processoriented teaching online teaching information systems for business requirements, functional requirements, performance requirements, security requirements analysis systems for the actual demand, and thus demand for the establishment of a corresponding functional model, given Teaching System use case analysis. System design phase are teaching management, learning management, curriculum management, communication management, system management detailed design shows a functional block diagram and IPO designing forms, ER diagrams and basic database table, and made a number of database optimization. Q through function security access control module, the main module completion process teaching and answering module implementations, and research key technical issues involved. The system uses J2EE + MVC model, the model is based on components, platformindependent system that can run on multiple operating systems such as windows, Linux, Unix, etc., using advanced architecture, ease of maintenance and development, improve efficiency but also to ensure the maintainability of the system security, scalability.

\section{References}

1. Maoyuan China popularization of higher education structures and systems. Guangzhou: Guangdong Higher Education Press, 14(2009)

2. Du to Germany, Yaoyuan Feng, Li Xing-Dong Toward Development of Adult Education. Beijing: China Renmin University Press, 267(2007)

3. He Qizong new era of education - theory and practice of lifelong education. Beijing: People's Publishing House, 23(2008)

4. Zhao new study occupational characteristics of the Adult Higher Education - Xiamen five universities, for example the status of implementation of Adult Higher Education. Xiamen University, master's thesis, 251(2007)

5. TURAL multimedia technology on Foreign Language Listening Course of Modern Languages (late), 05 (2006)

6. Feng. Foreign Language Teaching hear the application of multimedia teaching methods. Chinese education technology and equipment, 20, (2008)

7. Chen Zuohong multimedia use Advanced Speaking in Foreign Language Teaching. Research of National Education, 3 (2006)

8. Jiangde Yong. Discussion on the evaluation process implemented in the network education. Nanchang College of Education, 26 (2011)

9. Cai Jianwei. Construction of a new process of teaching evaluation platform. Xiang Chao, 84 (2011)

10. Song Jingyan distance education in the process of learning to guide the design. Business Modernization. 18 (2009)

11. Guo Yan Rui .J2EE and MVC Model in Campus Management System Development Information and Computer (Theory), 2 (2011) 